\title{
Supplement:
}

\section{Context-dependent reduction in somatic condition of wild Atlantic salmon infested with sea lice}

\author{
Roman Susdorf ${ }^{1,2}$, Nabeil K.G. Salama ${ }^{2}$, Christopher D. Todd ${ }^{3}$, Robert J. Hillman ${ }^{4}$, Paul Elsmere ${ }^{4}$ and \\ David Lusseau ${ }^{1}$ \\ 1 University of Aberdeen, School of Biological Sciences, Tillydrone Avenue, Aberdeen AB24 2TZ, UK \\ 2 Marine Scotland Science, Marine Laboratory, 375 Victoria Road, Aberdeen AB11 9DB, UK \\ ${ }^{3}$ Scottish Oceans Institute, School of Biology, University of St Andrews, St Andrews, Fife KY16 8LB, UK \\ ${ }^{4}$ Environment Agency, Sir John Moore House, Victoria Square, Bodmin, PL31 1EB, UK
}

Contact corresponding author: R.Susdorf@abdn.ac.uk 


\section{Supplement 1: Sample size (Tables S1 \& S2)}

Table S1: Sample size for one-sea-winter (1SW) and multi-sea-winter (MSW) salmon, for each site (Strathy Point (SP), North Esk (NE), Tamar (TA)) in each year used for the determination of a body condition index $K$ (weight at length).

*in Tamar each year was adjusted to match the cohort run-timing (mid March to mid March next year)

\begin{tabular}{|c|c|c|c|c|c|c|}
\hline & \multicolumn{2}{|c|}{ SP } & \multicolumn{2}{|c|}{ NE } & \multicolumn{2}{|c|}{$\mathrm{TA}^{*}$} \\
\hline & $1 \mathrm{SW}$ & MSW & 1SW & MSW & $1 \mathrm{SW}$ & MSW \\
\hline 1999 & 39 & - & & & & \\
\hline 2000 & 41 & - & & & & \\
\hline 2001 & 43 & - & 929 & 487 & & \\
\hline 2002 & 53 & - & 1437 & 731 & & \\
\hline 2003 & 63 & - & 1314 & 806 & 70 & 102 \\
\hline 2004 & 62 & - & & & 466 & 134 \\
\hline 2005 & 59 & - & & & 127 & 126 \\
\hline 2006 & 69 & - & & & 440 & 131 \\
\hline 2007 & 62 & - & & & 405 & 69 \\
\hline 2008 & & & & & 166 & 147 \\
\hline 2009 & & & & & 223 & 139 \\
\hline 2010 & & & & & 843 & 172 \\
\hline 2011 & & & & & 341 & 212 \\
\hline 2012 & & & & & 116 & 110 \\
\hline 2013 & & & & & 171 & 184 \\
\hline \multicolumn{7}{|l|}{2014} \\
\hline 2015 & & & & & 182 & 91 \\
\hline 2016 & & & & & 200 & 90 \\
\hline All & 491 & - & 3680 & 2024 & 3750 & 1707 \\
\hline
\end{tabular}

Table S2: Sample size for each component (1SW or MSW, female (F), male (M)) in each site with known infestation density $D$ used for the assessment of a potential effect from sea lice on condition $K$.

\begin{tabular}{|c|c|c|c|c|c|c|c|c|c|c|c|c|}
\hline \multicolumn{5}{|c|}{ Tamar } & \multicolumn{8}{|c|}{ North Esk } \\
\hline & \multicolumn{2}{|c|}{ 1SW } & \multicolumn{2}{|c|}{ MSW } & & & \multicolumn{3}{|c|}{ Male } & \multicolumn{3}{|c|}{ Female } \\
\hline $\begin{array}{c}\text { Season } \\
t\end{array}$ & $\mathbf{F}$ & $M$ & $\mathbf{F}$ & M & \multicolumn{2}{|c|}{ Month $m$} & 2001 & 2002 & 2003 & 2001 & 2002 & 2003 \\
\hline 1 & 0 & 0 & 184 & 60 & \multicolumn{2}{|c|}{ Apr/May } & 72 & 121 & 89 & 101 & 162 & 101 \\
\hline 2 & 286 & 128 & 378 & 249 & \multicolumn{2}{|c|}{ June } & 70 & 52 & 95 & 82 & 82 & 106 \\
\hline 3 & 979 & 633 & 129 & 66 & \multicolumn{2}{|c|}{ July } & 105 & 62 & 54 & 123 & 53 & 70 \\
\hline 4 & 279 & 278 & 54 & 30 & \multicolumn{2}{|c|}{ August } & 91 & 99 & 42 & 125 & 78 & 63 \\
\hline Sum & 1544 & 1039 & 745 & 405 & & & & 334 & 280 & 431 & 375 & 340 \\
\hline \multicolumn{13}{|c|}{ Strathy Point } \\
\hline \multirow[t]{2}{*}{ 1SW } & Month & $19 \mathrm{~s}$ & & 2000 & 2001 & 2002 & 2003 & 2004 & 2005 & 2006 & 2007 & Sum \\
\hline & June/Jul & 39 & & 41 & 43 & 53 & 63 & 62 & 59 & 69 & 62 & 491 \\
\hline
\end{tabular}




\section{Supplement 2: Body Condition index $K$ (Figure S1)}
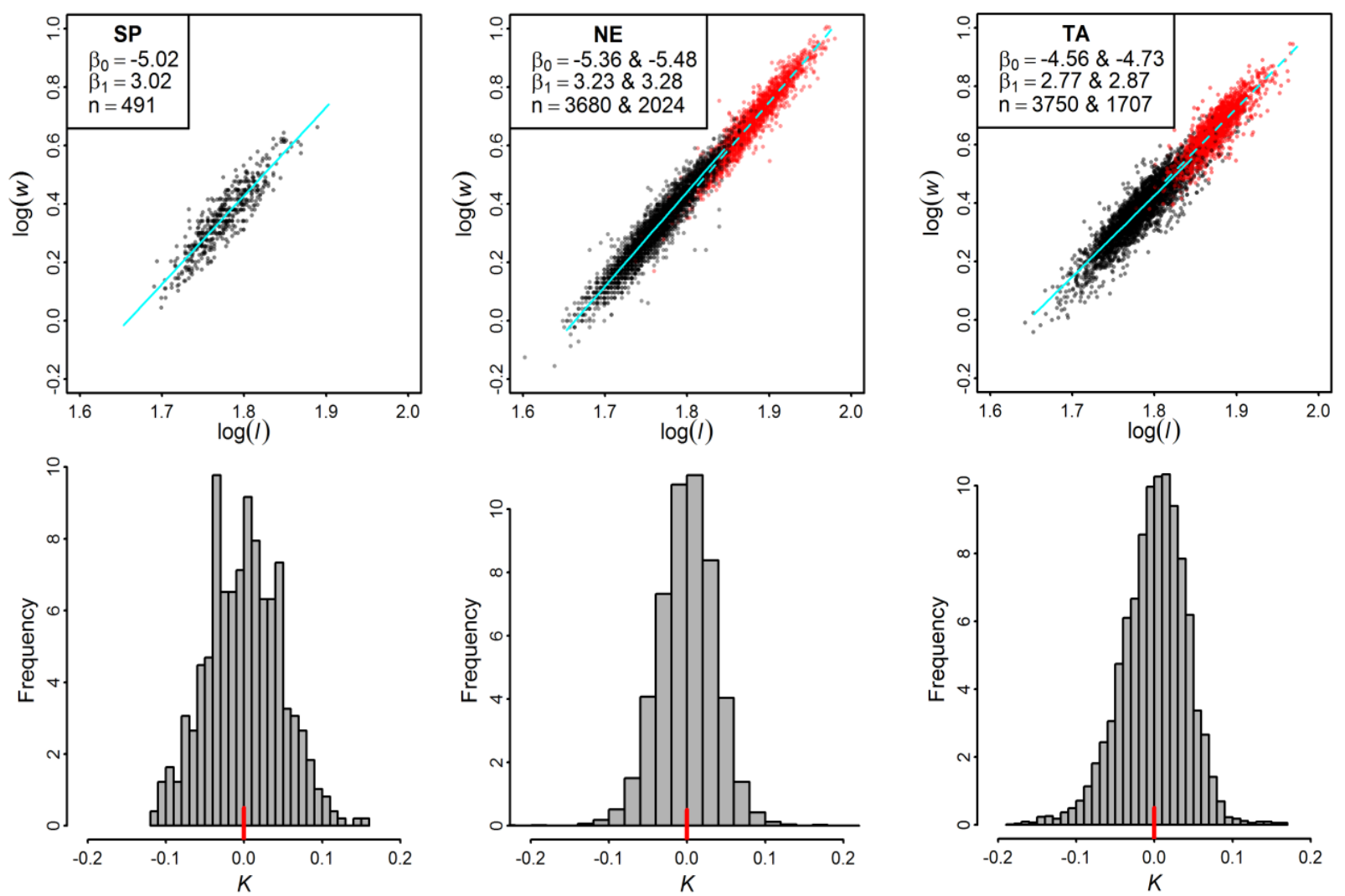

Figure S1: Top: Length-weight relationship (LWR, in $\mathrm{cm}$ and $\mathrm{kg}$, both $\log _{10}$-transformed) for $4911 \mathrm{SW}$ at Strathy Point (SP, left), 3680 1SW and 2024 MSW in North Esk (NE, centre), and 3750 1SW and 1707 MSW in Tamar (TA, right) according to Table S1. Each regression is described by intercept and slope parameters $\beta_{0}$ and $\beta_{1}$, whereas the LWR was obtained for each sea age class individually (regression line shown in solid (1SW) or dashed (MSW)). The residuals of each linear model are used as individual body condition index $K$.

The intercept and slope parameters $\beta_{0}$ and $\beta_{1}$ of the linear model for each catchment and sea age are $-5.02 \pm 0.11$ and $3.02 \pm 0.06$ (SP, $1 \mathrm{SW}),-5.36 \pm 0.03$ and $3.23 \pm 0.02$ (NE, $1 \mathrm{SW}$ ), $-5.48 \pm 0.04$ and $3.28 \pm 0.02$ (NE, MSW), as well as $-4.56 \pm 0.04$ and $2.77 \pm 0.02(T A, 1 S W)$, and $-4.73 \pm 0.07$ and $2.87 \pm 0.04(T A, M S W)$. The coefficient of determination $R^{2}$ for the relationship between $\log _{10}$-transformed $w$ and $\log _{10}$-transformed $l$ is 0.82 (SP, 1SW), 0.91 (NE, 1SW), 0.92 (NE, MSW), 0.8 (TA, 1SW) and 0.77 (TA, MSW).

Bottom: $K$ distribution for SP (left), NE (centre) and TA (right) with mean being depicted as vertical bar around zero. 


\section{Supplement 3: Determination of sea age in North Esk (NE) and Tamar (TA)}

\section{A. North Esk (Figure S2+S3)}

The North Esk (NE) sample consisted of 1SW ( $n=3677), 2 S W(n=2000), 3 S W(n=13)$, and 14 (out of overall 5704) individuals with missing sea age $(a)$ information (Figure S3). As preliminary analysis revealed that $a$ should be considered as covariate to describe a potential effect from sea lice on host condition $K$, missing $a$ values in the NE sample were determined in two steps using a mixture model.

\section{Step 1: manual determination}

Beforehand, the data were treated: as the weight and length of 3SW individuals is not readily distinguishable from $2 \mathrm{SW}$, both age-classes were compiled into a single category: multi sea-winter (MSW) fish. Then the length $l$ density distribution (kernel) for each month $m$, year $y$, and sex $s$ was used to manually assign a specific length-threshold (near the lowest density ( $y$-axis) between the two density peaks) which is assumed to split 1SW from MSW. Accordingly, all 5704 individuals were preliminary clustered into 2 components representing 1SW (all fish below the $m$-, $y$-, and $s$-specific length-threshold) and MSW (all fish above) (Figure S2). Here, $l$ was chosen over weight $w$ as it is a slightly better predictor of sea-age (adjusted $R^{2}$ of 0.85 vs 0.83 , both $p \approx 0$ ). A comparison with known sea age values resulted in an overlap of $98 \%$, validating the accuracy of this method. However, under the underlying assumption the lengths of the two sea age classes in each $m, y$, and for each $s$ are strictly separated and not allowed to overlap, which is inappropriate. Furthermore, this coarse approach is prone to biases with regards to the chosen length-thresholds. Nevertheless, it provides an initial probability of an individual belonging to the 1SW or MSW group, which is important information required for an accurate algorithmic sea age assessment (see Step 2). These initial $a$ estimates were adopted in the 14 individuals missing this parameter; i.e. for the remaining 5690 fish $a$ as determined from scale reading was restored.

\section{Step 2: algorithmic determination}

A Gaussian mixture model with 2-components (1SW and MSW) (R-package flexmix (Leisch 2004; Grün \& Leisch 2008) v.2.3-13) with length $l$ as response, and Day of the Year ( $d$ ) (numerical), year $y$ (categorical), and sex $s$ (categorical) as predictor variables (selection based on AIC) was fitted. However, this basic model performed poorly:

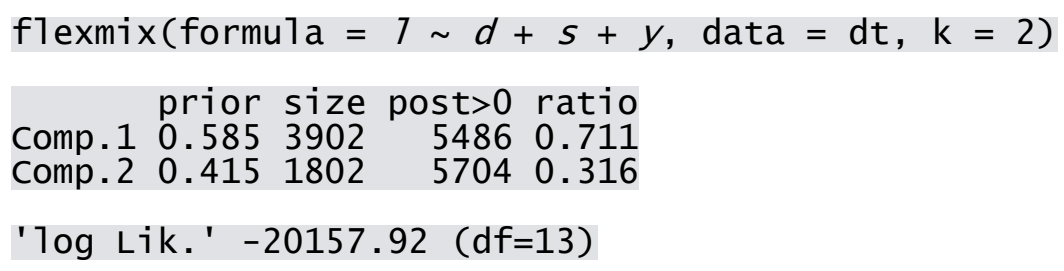


AIC: 40341.83 BIC: 40428.27

A relatively small proportion of observations with non-vanishing posteriors (post $>0$ in model summary) is assigned to each cluster (ratio of 0.711 (1SW) and 0.316 (MSW)), suggesting a big overlap between age classes. Overall, the model predicted unrealistic sea age values and needed improvement.

Thus, actually measured $(n=5690)$ and manually determined $(n=14) a$ values (from Step 1 ) were used to assign an initial probability of component membership for each individual in form of a twoelement vector containing ( $o s w=1, m s w=0$ ) for $1 S W$ and ( $o s w=0, m s w=1$ ) for $M S W$. This resulted in a two-column matrix with 5704 (NE sample size) rows. This by far improved the performance of the EM algorithm with observations being assigned to the corresponding cluster at a ratio of 0.83 (Comp.1=1SW) and 0.72 (Comp.2=MSW):

flexmix(formula $=7 \tilde{d}+s+y$, data $=d t, k=2$, cluster $=$ matrix $(c(d t \$ 0$ sw, dt\$msw), 5704, 2))

prior size post $>0$ ratio

Comp.1 $0.6603755 \quad 4543 \quad 0.827$

Comp.2 $0.3401949 \quad 27230.716$

' log Lik.' -20176.74 ( $d f=13)$

AIC: 40379.48 BIC: 40465.92

A comparison between modelled and known $a$ values validated the model (precision of $>98 \%$ ).

The obtained $a$ values were applied (only) in the corresponding 14 individuals for further analysis. 

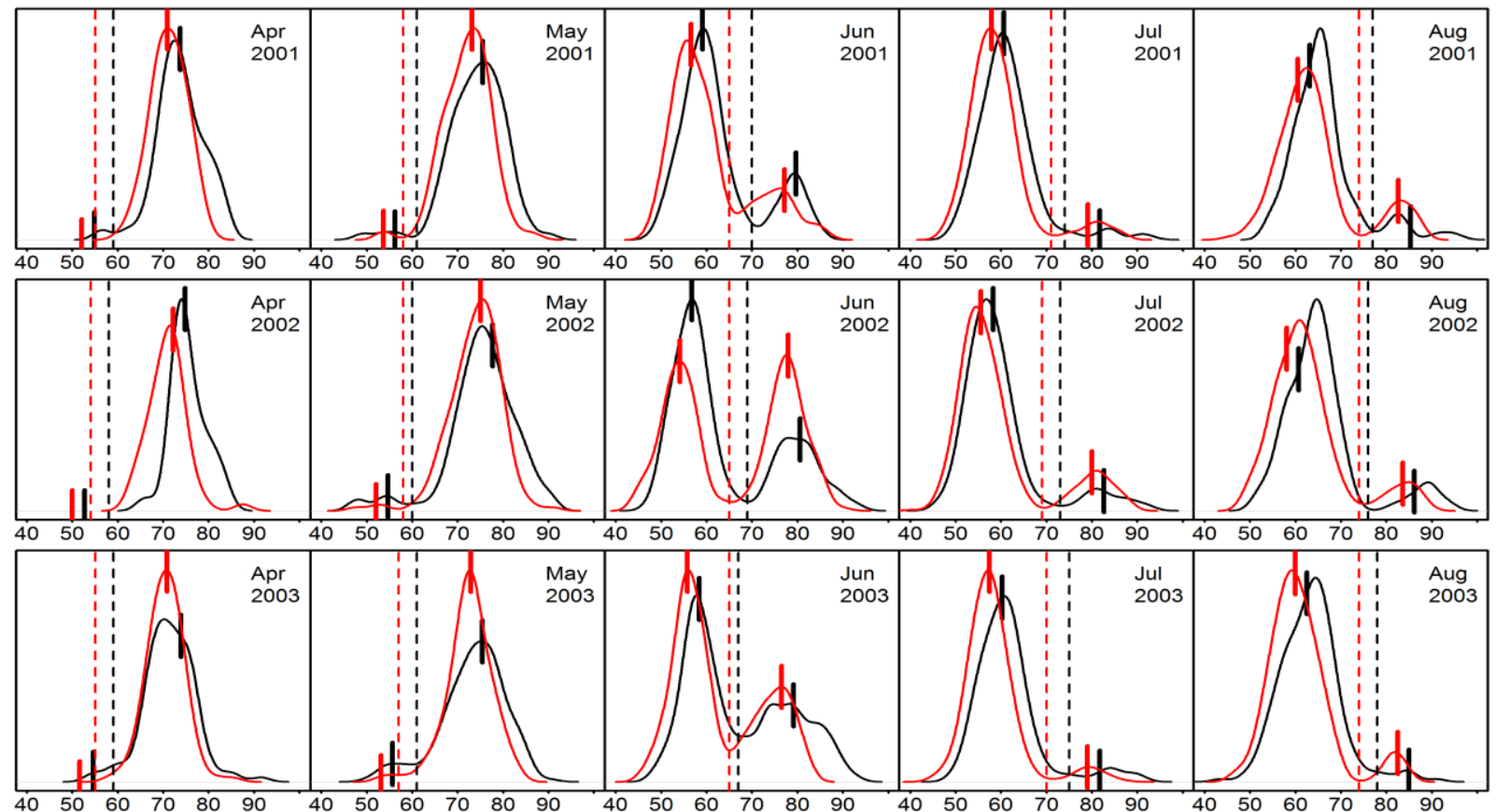

Figure S2: Length density distribution of male (black) and female (red) Atlantic salmon from NE catchment ( $n=5704)$ in each month and year. Dotted vertical lines are length-thresholds chosen manually to separate between 1SW (below threshold) and MSW (above threshold). The short bold vertical lines are median lengths for 1SW and MSW as predicted by the Gaussian mixture model.

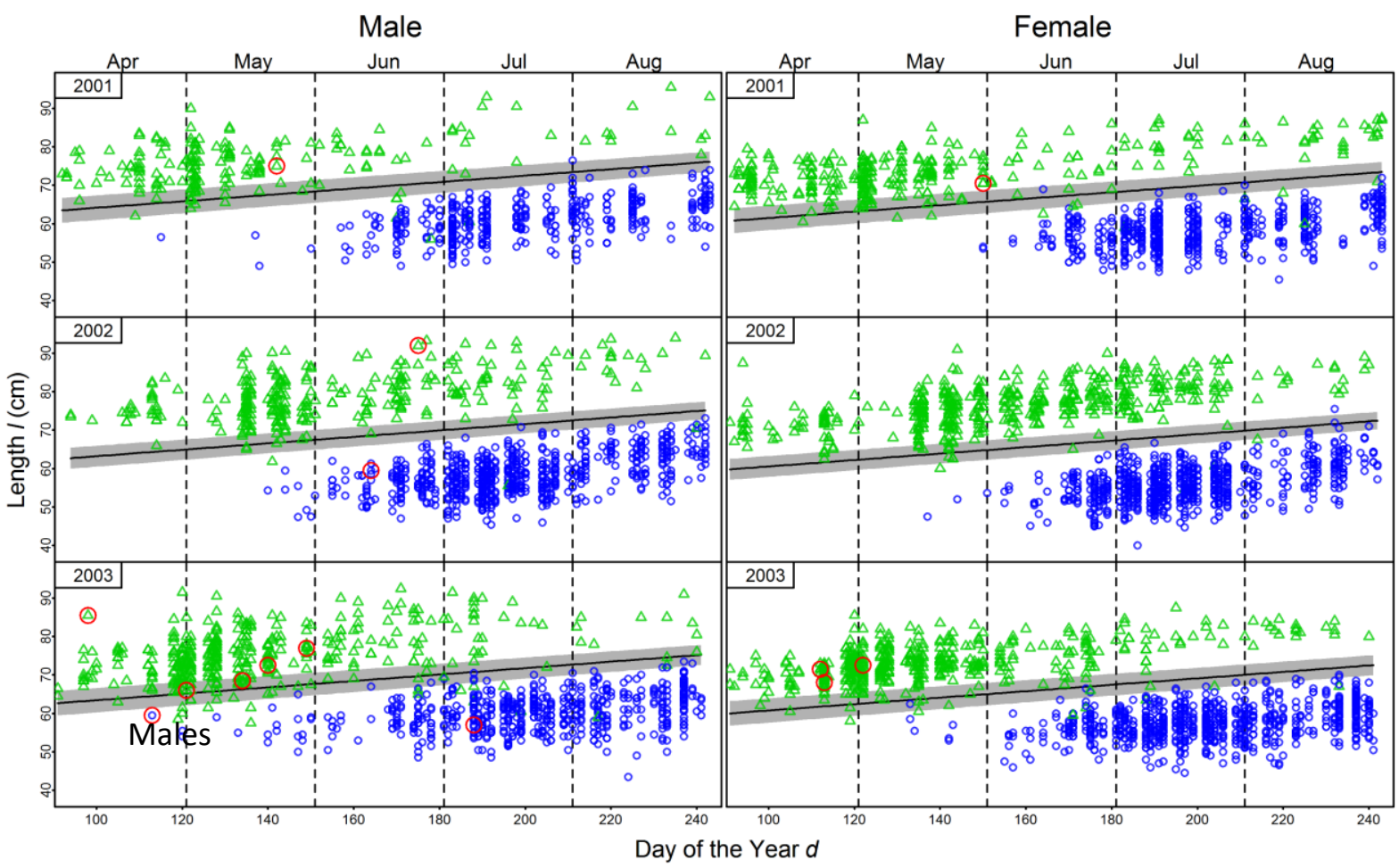

Figure S3: Day of the Year $d$ of freshwater entry (i.e. sampling date) (x-axis) and length $l$ (y-axis) in $\mathrm{cm}$ of sampled male (left) and female (right) Atlantic salmon ( $n=5704)$ in River North Esk. 1SW are plotted as blue circles, and MSW as green triangles. In individuals with missing information on sea age (a) (highlighted in red) it was estimated using a Gaussian mixture model. All individuals below or above the grey band are assigned as 1SW or respectively MSW with a probability of over $95 \%$. 


\section{B. Tamar (Figure S4, Table S3)}

The Tamar (TA) sample consisted of 1SW ( $n=3595), 2$ SW ( $n=1533), 3 S W(n=9)$, and 583 (out of overall 5720) individuals with missing sea age (a) information (Figure S4). Spawning takes place around November-December each year. However, the migration of each cohort can extend from about March in one year to March the next year, with fish entering freshwater after November being most likely to postpone spawning until the subsequent spawning season. Date (Day of the Year $d$ ) in each year was adjusted to contain the whole migration period, i.e. starting in $d=73$ (mid March) in each year and ending in $d=365+73$ (mid March) (referred to as $d_{a d j}$ ) of the next. Year $y$ was adjusted according to this shift by 73 days (referred to as $y_{a d j}$ ), so that the whole cohort (running from e.g. March 2011 to March 2012) was assigned a $y_{a d j}$ of 2011. Like in the NE sample, sea age $a$ had to be first determined manually based on length $l$ of each $a$-class at any sampling date in each year, as otherwise the EM algorithm didn't perform appropriately.

\section{Step 1: manual determination}

For a manual determination of $a, 2 \mathrm{SW}$ and $3 \mathrm{SW}$ were compiled into a single category MSW. Then the scatterplot of length $l$ vs adjusted day of sampling $d_{a d j}$ in each adjusted year $y_{a d j}$ was used to manually determine a linear model of the form $l=\beta_{0}+d_{a d j} \beta_{1}$ to segregate 1SW from MSW (Figure S4). Chosen intercept and slope parameters for each year are given in Table S3. All individuals with missing $a$ (Figure S4, red circles) below the $y_{a d j}$ - and $d_{a d j}$-specific length-threshold (defined by the linear model) were treated as 1SW, and all fish (with missing $a$ ) above as MSW. A comparison with known sea age values resulted in an overlap of $98 \%$, validating the accuracy of this method.

Table S3: Annual intercept and slope coefficients of the linear models with predictor $d_{a d j}$ (adjusted Day of the Year) and response $l$ used to manually assign sea age to salmon which were missing this information $(n=583)$.

\begin{tabular}{|l|l|l|}
\hline Year (adj) & Intercept $\beta_{0}$ & Slope $\beta_{1}$ \\
\hline 2003 & 52 & 0.091 \\
\hline 2004 & 47 & 0.118 \\
\hline 2005 & 49 & 0.1 \\
\hline 2006 & 46 & 0.111 \\
\hline 2007 & 47 & 0.1 \\
\hline 2008 & 53 & 0.071 \\
\hline 2009 & 53 & 0.067 \\
\hline 2010 & 54 & 0.067 \\
\hline 2011 & 51 & 0.083 \\
\hline 2012 & 52 & 0.067 \\
\hline 2013 & 53 & 0.059 \\
\hline 2015 & 54 & 0.059 \\
\hline 2016 & 52 & 0.071 \\
\hline
\end{tabular}

\section{Step 2: algorithmic determination}

Fitting a Gaussian mixture model with 2-components (1SW and MSW) (R-package flexmix (Leisch 2004; Grün \& Leisch 2008) v.2.3-13) with length $l$ as response, and Day of the Year $\left(d_{a d j}\right)$ (numerical), year $y_{a d j}$ (categorical) and Fulton's condition index $K_{F}$ as predictor variables initially performed poorly:

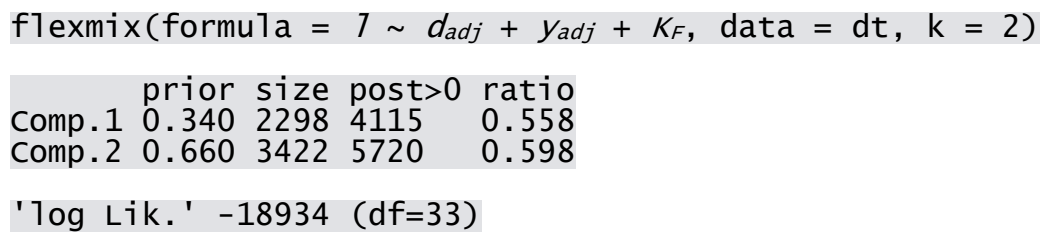


Only a relatively small proportion of observation with non-vanishing posteriors ( 0.558 and 0.598 ) could be assigned a sea age class. Many of the obtained sea age values were clearly wrong.

Like in NE, in an attempt to improve the mixture model, we used the actually measured $(n=5137)$ and manually determined ( $\mathrm{n}=583) a$ values (from step 1 ) to assign an initial probability of component membership for each individual in form of a two-element vector containing (osw $=1$, $m s w=0$ ) for $1 S W$ and (osw=0, $m s w=1$ ) for $M S W$. But this additional information did not resolve the poor performance of the model:

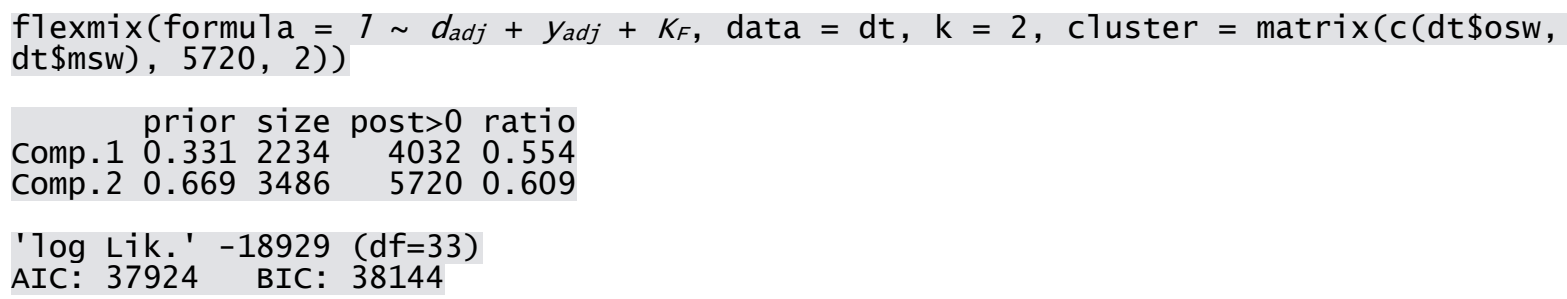

However, model performance was satisfying after adjusting a hyperparameter for the EM algorithm by using "hard" assignment of manually obtained $a$-values to clusters:

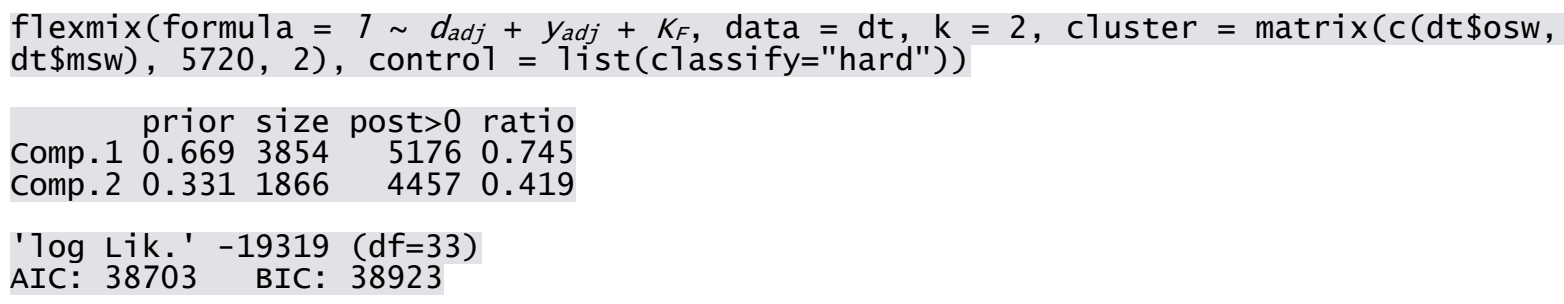

A comparison between modelled and known $a$ values validated the model (precision of $>95 \%$ ). The obtained $a$ values were applied (only) in the corresponding 583 individuals (red circles in Figure S4) for further analysis. 


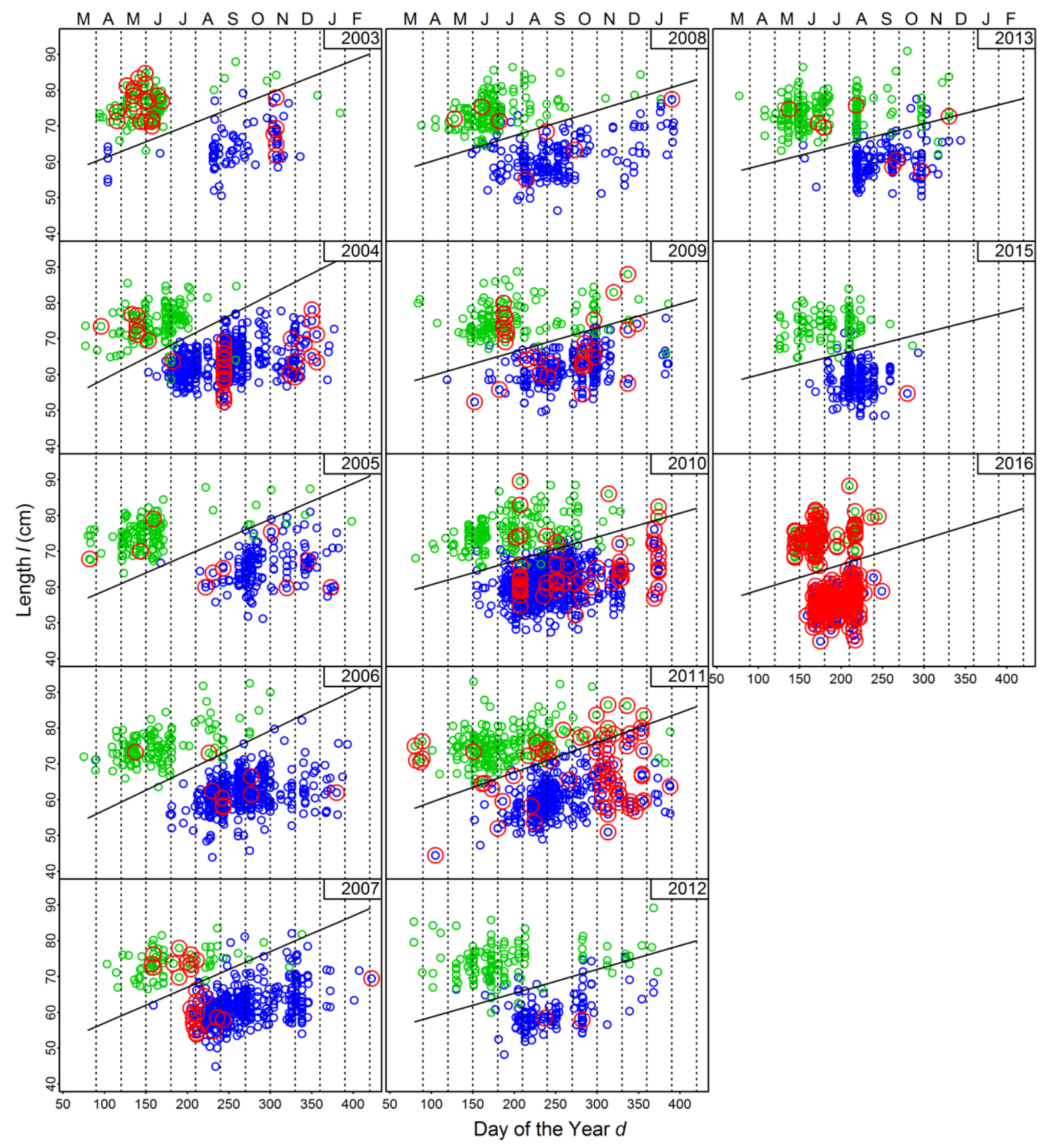

Figure S4: Length $l(\mathrm{~cm})$ vs sampling date $d_{a d j}$ (adjusted Day of the Year) for 1SW (blue dots) and MSW (green dots) in each year (adjusted from March to March next year to match the salmon cohort migration time). The lines segregating 1SW from MSW were chosen manually, by applying a linear model with $l$ as response and $d_{a d j}$ as predictor $\left(l=\beta_{0}+d_{a d j} \beta_{1}\right)$. Model coefficients are shown in Table S3. Individuals with missing sea age values (red circles, $n=583$ ) were categorised based on whether they were located below (1SW) or above the line (MSW). 


\section{Supplement 4: Final model diagnostics (Table S4-6, Figure S5-7)}

\section{A. Strathy Point}

Table S4: Details for linear mixed effects model used to quantify the sea lice-mediated condition effect on 1SW Atlantic salmon sampled at SP $(n=491,1999-2007)$. Covariates used are infestation density $D$ (mobile sea lice/ $\mathrm{kg}$, scaled), proportion of adult female $L$ salmonis $(\theta$, scaled) and sampling year $(y)^{\mathrm{F}}$ as random intercepts.

$\mathrm{F}$ : applied as factor

\begin{tabular}{|c|c|c|c|c|}
\hline \multicolumn{5}{|l|}{ Strathy Point } \\
\hline \multicolumn{5}{|c|}{$K \sim D+\theta+D \theta+(\theta \mid y)$} \\
\hline \multicolumn{5}{|l|}{ Residuals: } \\
\hline Min $\quad 10$ & \multirow{2}{*}{\multicolumn{4}{|c|}{ Median 3Q Max }} \\
\hline$-0.107-0.0256$ & & & & 0.169 \\
\hline \multicolumn{5}{|l|}{ Random effects } \\
\hline \begin{tabular}{l|l} 
Groups & \\
\end{tabular} & Name & \multicolumn{2}{|l|}{ StdDev } & Corr \\
\hline \multirow[b]{2}{*}{$y$} & Intercept & \multicolumn{2}{|l|}{0.02965} & \multirow{2}{*}{-0.01} \\
\hline & $\theta$ & \multicolumn{2}{|l|}{0.00777} & \\
\hline \multicolumn{2}{|l|}{ Residual } & 0.03663 & & \\
\hline \multicolumn{5}{|c|}{ No of observations: 491 ; Groups: $y=9$} \\
\hline \multicolumn{5}{|c|}{ Fixed effects (model average) } \\
\hline Coefficient & Estimate & StdErr & z-val & $\mathrm{p}$ \\
\hline Intercept & 0.00385 & 0.009793 & 0.392 & 0.695 \\
\hline$D$ (scaled) & -0.01046 & 0.001921 & 5.434 & $<0.001$ \\
\hline$\theta$ (scaled) & 0.002106 & 0.002795 & 0.752 & 0.452 \\
\hline$D \theta$ & -0.001718 & 0.002106 & 0.815 & 0.415 \\
\hline \multicolumn{5}{|c|}{ Marginal R-squared: 0.047 (fixed effects only) } \\
\hline \multicolumn{5}{|c|}{ Conditional R-squared: 0.454 (fixed and random effects) } \\
\hline
\end{tabular}
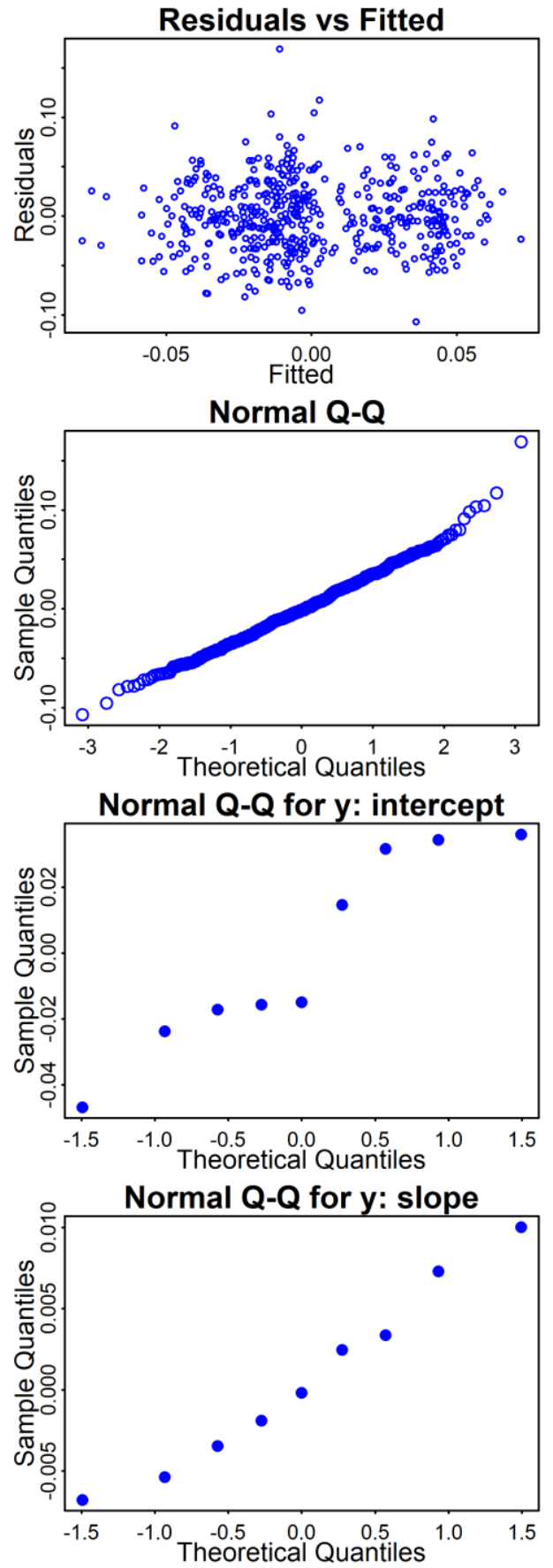

Figure S5: Diagnostic plots for linear mixed effects model of condition $K$ for Strathy Point 1SW salmon (Table S4). 


\section{B. North Esk}

Table S5: Details for averaged linear model used to quantify the effect from sea lice density $D$ on salmon condition $K$ in NE ( $n=952$ male and 1146 female salmon, 2001-2003). Covariates used: infestation intensity $D$ (mobile sea lice $/ \mathrm{kg}$ ), year of sampling $(y)^{\mathrm{F}}$, sex $(s, \text { male }=1 \text {, female }=2)^{\mathrm{F}}$, sampling month $(m)^{\mathrm{F}}$.

$\mathrm{F}$ : applied as factor

\begin{tabular}{|c|c|c|c|c|}
\hline \multicolumn{5}{|l|}{ North Esk } \\
\hline \multicolumn{5}{|c|}{$K \sim D+y+s+m+D y+D m+D s+y m$} \\
\hline $\begin{array}{ll}\text { Residuals: } \\
\text { Min } & 10 \\
-0.2511 & -0\end{array}$ & $\begin{array}{lr} & \text { Median } \\
22 & 0.00099\end{array}$ & $\begin{array}{ll}3 Q & M c \\
0.0228 & 0.1\end{array}$ & & \\
\hline Coefficient & Estimate & Adj. StdErr & t-val & $p$ \\
\hline Intercept & -0.00823 & 0.003034 & 2.712 & 0.007 \\
\hline$D$ & 0.00161 & 0.000989 & 1.63 & 0.103 \\
\hline$m 6$ & 0.00871 & 0.004518 & 1.928 & 0.053 \\
\hline$m 7$ & -0.00002 & 0.003925 & 0.005 & 0.999 \\
\hline$m 8$ & 0.00810 & 0.003889 & 2.082 & 0.037 \\
\hline$s 2$ & 0.007631 & 0.001745 & 4.373 & $<0.001$ \\
\hline$y 2002$ & 0.017882 & 0.003594 & 4.976 & $<0.001$ \\
\hline$y 2003$ & -0.00331 & 0.00391 & 0.845 & 0.398 \\
\hline$D: m 6$ & -0.00024 & 0.000912 & 0.26 & 0.795 \\
\hline$D: m 7$ & -0.00226 & 0.001056 & 2.141 & 0.0323 \\
\hline$D: m 8$ & -0.00326 & 0.001106 & 2.95 & 0.0032 \\
\hline D:y2002 & -0.00215 & 0.000908 & 2.368 & 0.0178 \\
\hline$D: y 2003$ & -0.00285 & 0.000825 & 3.45 & $<0.001$ \\
\hline$m 6: y 2002$ & -0.01026 & 0.00561 & 1.829 & 0.067 \\
\hline$m 7: y 2002$ & -0.00645 & 0.005314 & 1.215 & 0.224 \\
\hline$m 8: y 2002$ & -0.00132 & 0.00494 & 0.266 & 0.79 \\
\hline$m 6: y 2003$ & -0.01158 & 0.005552 & 2.085 & 0.037 \\
\hline$m 7: y 2003$ & 0.010247 & 0.005549 & 1.847 & 0.065 \\
\hline$m 8: y 2003$ & -0.00933 & 0.005652 & 1.651 & 0.099 \\
\hline $\begin{array}{l}\text { Residual } \\
\text { standard } \\
\text { error: } 0.035\end{array}$ & $\begin{array}{l}\text { Multiple R- } \\
\text { squared: } \\
0.105\end{array}$ & $\begin{array}{l}\text { Adjusted R- } \\
\text { squared: } \\
0.097\end{array}$ & $\begin{array}{l}\text { F- } \\
\text { statistic: } \\
13.3 \text { on } \\
18 \text { or } 19 \\
\text { and } \\
2079 \mathrm{DF}\end{array}$ & $\begin{array}{l}\text { p-value: } \\
<2.2 \mathrm{e}-16\end{array}$ \\
\hline
\end{tabular}

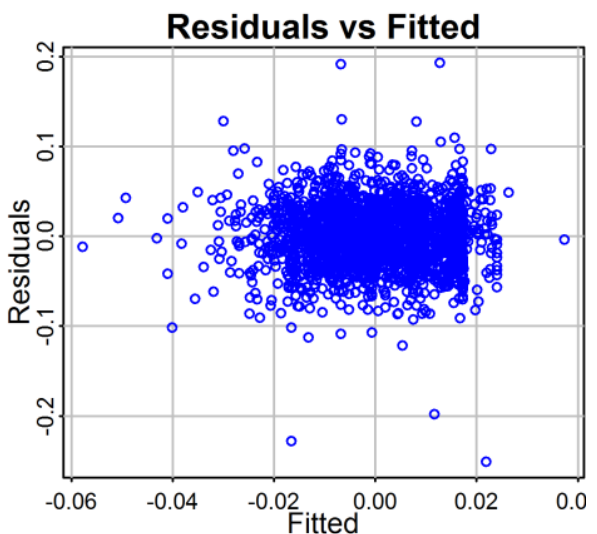

Normal Q-Q

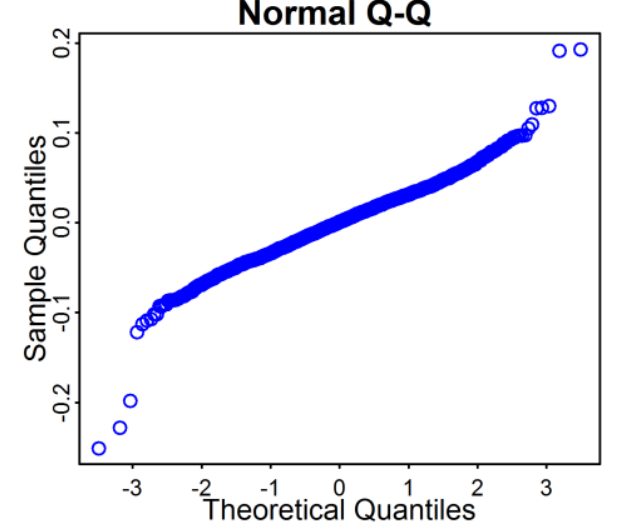

Figure S6: Diagnostic plots for the average linear model of condition $K$ for North Esk salmon (Table S5). 


\section{Tamar}

Table S6: Details for the averaged ("full" (in contrast to "subset") average) linear mixed effects model on the influence of infestation $D$ on 1 SW salmon condition $K$ in River Tamar (TA). Covariates used are sea lice density ( $D$, lice $/ \mathrm{kg}$ ), year of sampling $(y)^{\mathrm{F}}$ as random effect, $\operatorname{sex}(s \text {, male }=1 \text {, female }=2)^{\mathrm{F}}$ and season ( $t$, Mar-May=1 (MSW only), Jun-Jul=2, Aug-Sep=3, Oct-Nov=4) ${ }^{\mathrm{F}}$. F: applied as factor

\begin{tabular}{|c|c|c|c|c|c|}
\hline \multicolumn{6}{|c|}{$\begin{array}{l}\text { Tamar 1SW } \\
K \sim D+s+t+s t+D s+D t+(1 \mid y / t)\end{array}$} \\
\hline \multicolumn{6}{|l|}{ Scaled residuals: } \\
\hline Min $\quad 10$ & Median & 30 & \multicolumn{2}{|l|}{ Max } & \\
\hline-0.55 & 0.07 & 0.62 & \multicolumn{2}{|l|}{4.24} & \\
\hline \multicolumn{6}{|c|}{ Random effects } \\
\hline Groups & \multicolumn{2}{|l|}{ Name } & \multicolumn{2}{|c|}{ Variance } & StdDev \\
\hline$t: y$ & \multicolumn{2}{|l|}{ Intercept } & \multicolumn{2}{|c|}{0.000112} & 0.0106 \\
\hline$y$ & \multicolumn{2}{|c|}{ Intercept } & \multicolumn{2}{|c|}{0.000123} & 0.0111 \\
\hline \multicolumn{3}{|c|}{ Residual } & \multicolumn{2}{|c|}{0.001462} & 0.0382 \\
\hline \multicolumn{6}{|c|}{ No of observations: 2583 ; Groups: $t: y=34 ; y=12$} \\
\hline \multicolumn{6}{|c|}{ Fixed effects (model average) } \\
\hline Coefficient & \multicolumn{2}{|c|}{ Estimate } & StdErr & z-val & $\mathrm{p}$ \\
\hline (Intercept) & \multicolumn{2}{|c|}{-0.0031} & 0.005595 & 0.553 & 0.58 \\
\hline$D$ & \multicolumn{2}{|c|}{-0.0013} & 0.000499 & 2.603 & $<0.01$ \\
\hline$s 2$ & \multicolumn{2}{|c|}{0.0088} & 0.00341 & 2.579 & $<0.01$ \\
\hline t3 & \multicolumn{2}{|c|}{0.00018} & 0.005547 & 0.032 & 0.97 \\
\hline$t 4$ & \multicolumn{2}{|c|}{-0.03111} & 0.006278 & 4.953 & $<0.001$ \\
\hline$s 2: t 3$ & \multicolumn{2}{|c|}{0.00126} & 0.003182 & 0.396 & 0.69 \\
\hline$s 2: t 4$ & \multicolumn{2}{|c|}{0.00262} & 0.004897 & 0.534 & 0.59 \\
\hline$D: S 2$ & -0.0 & 00012 & 0.000358 & 0.033 & 0.97 \\
\hline$D: t 3$ & 0.0 & 0037 & 0.000321 & 0.117 & 0.91 \\
\hline$D: t 4$ & 0.0 & 0004 & 0.000349 & 0.013 & 0.99 \\
\hline & Marginal R-s & quared: & 103 (fixed effect & only) & \\
\hline Condit & tional R-squ & ared: 0. & (fixed and ran & $n$ effects) & \\
\hline
\end{tabular}

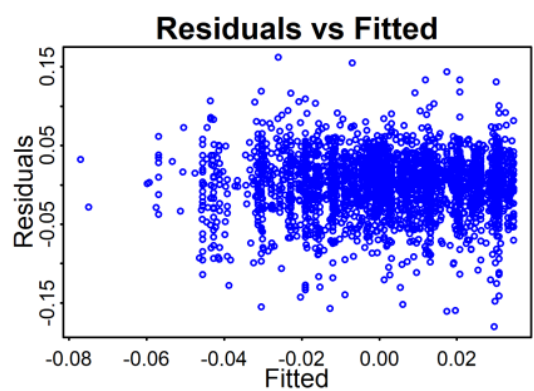

Normal Q-Q

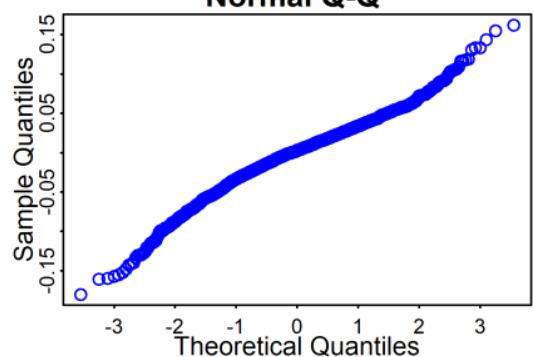

Normal Q-Q for t:y

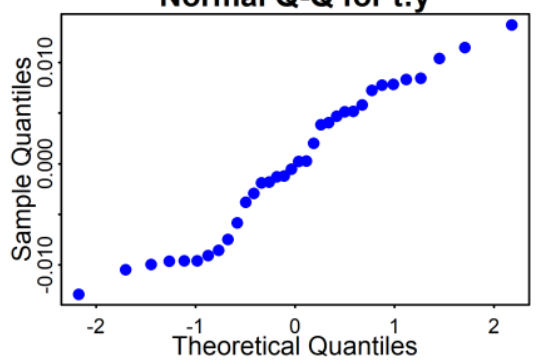

Normal Q-Q for $y$

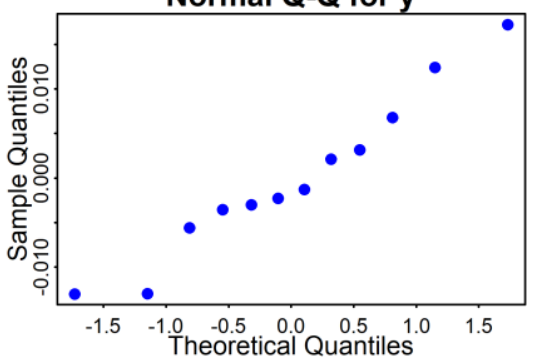

Figure S7: Diagnostic plots for the averaged mixed effects model ("full" (in contrast to "subset" average)) of condition $K$ for $1 \mathrm{SW}$ salmon from River Tamar (Table S6). 
Table S7: Details for the averaged ("full" (in contrast to "subset") average) linear mixed effects model on the influence of infestation $D$ on MSW salmon condition $K$ in River Tamar (TA). Covariates used are sea lice density ( $D$, lice $/ \mathrm{kg}$ ), year of sampling $(y)^{\mathrm{F}}$ as random effect, $\operatorname{sex}(s \text {, male }=1 \text {, female }=2)^{\mathrm{F}}$ and season ( $t$, Mar-May=1 (MSW only), Jun-Jul=2, Aug-Sep=3, Oct-Nov=4) ${ }^{\mathrm{F}}$.

$\mathrm{F}$ : applied as factor

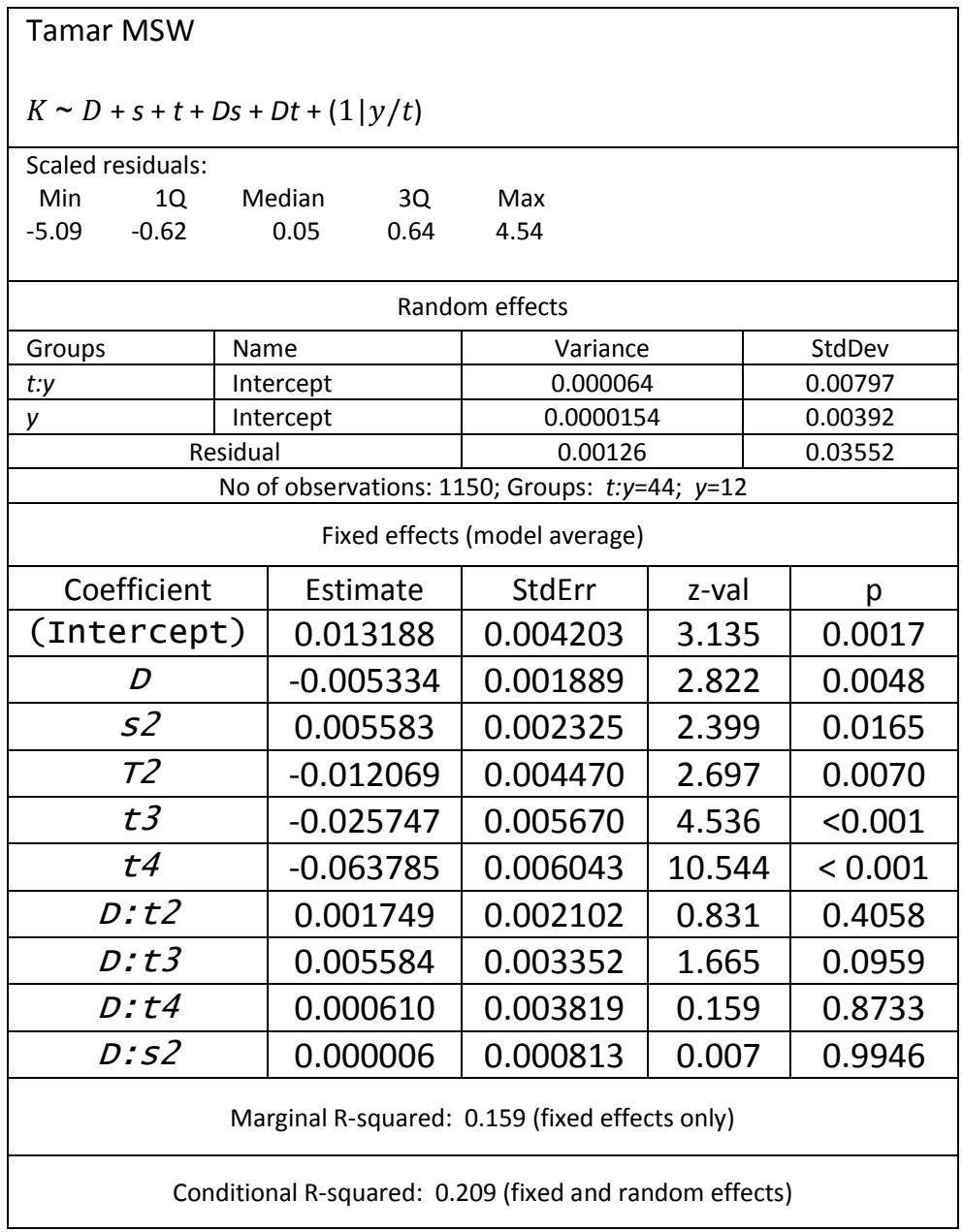

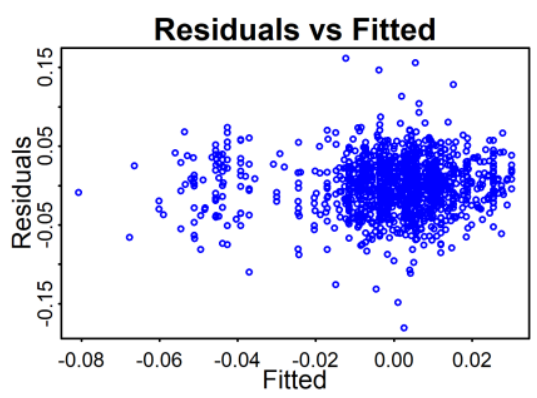

Normal Q-Q

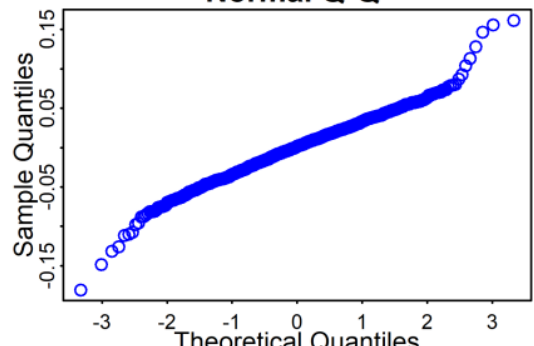

Normal Q-Q for t:y

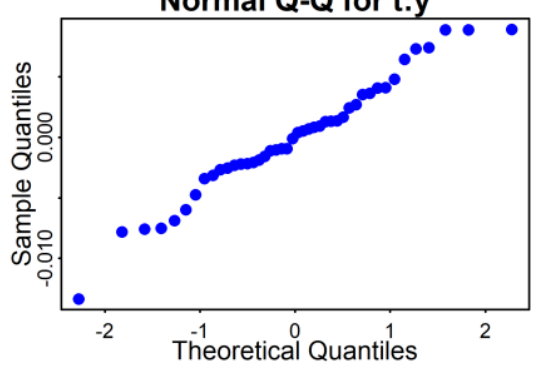

Normal Q-Q for y

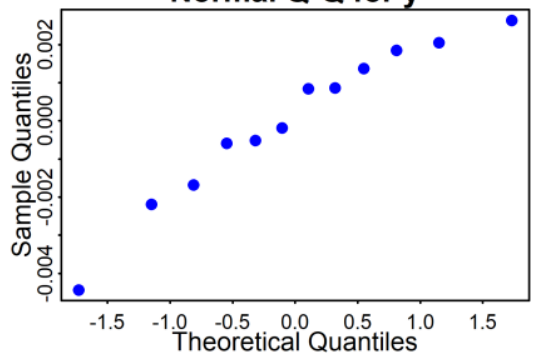

Figure S8: Diagnostic plots for the averaged mixed effects model ("full" (in contrast to "subset" average)) of condition $K$ for MSW salmon from River Tamar (Table S7). 


\section{Supplement 5: Infestation levels (Figure S9)}
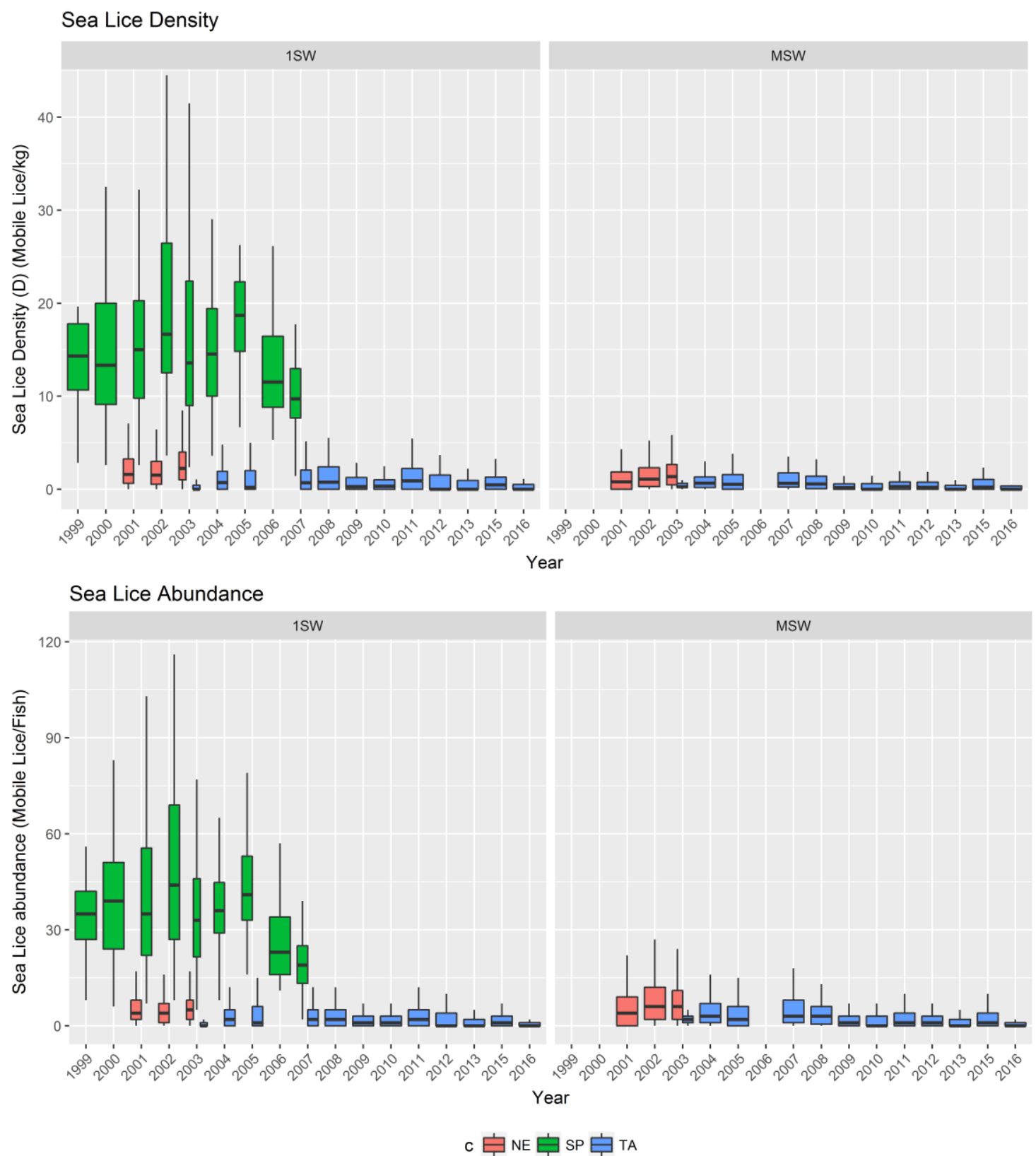

Figure S9:

Density ( $D$, lice/ $\mathrm{kg}$, top) and abundance (lice/fish, bottom) of mobile sea lice (all species combined) infesting Atlantic salmon sampled at the coast of Strathy Point (N Scotland, $n=491$ (1SW only), 1999-2007, green), estuary of River North Esk (E Scotland, $n=2077,2001-2003$, red) and estuary of River Tamar (S England, $n=3942,2003-2005,2007$ 2013,2015,2016, blue). 